\title{
RESENHAS
}

\section{AÇÃO AFIRMATIVA NO ENSINO SUPERIOR BRASILEIRO}

Jonas Zoninsein e João Feres Júnior

(orgs.)

Belo Horizonte: Editora UFMG; Rio de

Janeiro: luperJ, 2008, 350p.

$\mathrm{Na}$ introdução do livro - fruto da $2^{\mathrm{a}}$ Conferência Internacional da Rede de Estudos sobre Ação Afirmativa, realizada no Rio de Janeiro, em 2006 - são apresentadas reflexões que, em síntese, fornecem o ponto-chave que deve orientar o olhar do leitor, e, de forma mais ampla, podem guiar os estudos realizados no Brasil: a necessidade de problematizar as ações afirmativas no campo das políticas sociais.

Trata-se de uma perspectiva relevante, pois desde a década de 1990, quando se instaurou definitivamente o debate sobre ações afirmativas no Brasil, os primeiros trabalhos produzidos, ainda muito incipientes diante do ineditismo do tema e da escassez de material empírico a ser analisado, giravam em torno de algumas questões recorrentes acerca das possibilidades de adoção dessas medidas em um país de vasta classificação cromática, da constitucionalidade destas ações ou, ainda, apresentavam estudos de poucas ações isoladas levados a diante por segmentos da sociedade civil, em especial pré-vestibulares para negros e carentes.

Após uma década, já se encontra no Brasil um conjunto estabelecido de experiências de ação afirmativa, que se ainda não chegou ao que se espera, ao menos indica que há um caminho traçado.

Os artigos que integram o livro, ao se deslocar da perspectiva tradicional, refletem a consolidação e o amadurecimento intelec- tual sobre o tema que ocorrem no período, evidenciando uma segunda etapa de pesquisas e reflexões que corrobora a ideia de que as ações afirmativas devem também ser analisadas como parte de um projeto político.

Essa ruptura permite observar o processo de criação e de implementação de ações afirmativas como estratégia política que se, por um lado, evidencia uma orientação para a promoção de equidade em quaisquer das relações sociais em que se presencie algum tipo de subrepresentação proposital, ou exclusão e desprestígio históricos, por outro, explicita os arranjos ideológicos e orientação dos governos que as implementam.

Assim, há no livro um significativo diálogo com experiências nacionais diferentes daquelas já conhecidas como "modelo americano de ações afirmativas", configurando um campo de trocas eclético, mas que não necessariamente promove uma recusa à realidade norte-americana. De modo geral, no debate público, em que muito se questiona a adoção dessas iniciativas políticas, passa-se a admitir que elas não seriam mais uma expressão da adoção ingênua de padrões americanófilos, que se sobreporiam à realidade social, cultura e racial brasileira. Segundo as críticas, parece que seria mais uma imposição advinda de uma sociedade racialmente bipartida e absorvida de forma acrítica por uma sociedade multicolor de perfil racial indefinido. E mais, tal adoção levaria à instauração de uma lógica igualmente polarizada, além de estabelecer um modelo específico de classificação racial, até então inexistente.

Nesse aspecto, o livro organizado por Zoninsein e Feres aponta acertadamente para o fato de que as medidas americanas são inegavel- 
mente uma referência para o debate; contudo, referência não se subsume a padrão. Ela serve, assim, como um modelo de reflexão, muito mais que uma regra a ser aplicada. E, em busca de outras reflexões, o livro se estende à observação de experiências na América Latina, nos artigos de J. Michael Turner e de Luiz Fernando Martins da Silva e, na Índia, de Thomas E. Weisskopf.

Tendo como objetivo trazer novos elementos para a discussão e sem pretender comparações estreitas e definitivas com o Brasil, esses três textos abrem espaço para alternativa analítica em que o maior ganho se apresenta na leitura das entrelinhas.

No artigo de Weisskopf, tão relevante quanto o processo de inclusão de dalits e adivasis no ensino superior é a reflexão feita sobre o papel do Estado e, mais acertado seria dizer, são as reflexões sobre as ações do Estado, seus limites e as diferentes possibilidades de ações afirmativas decorrentes. Comparando os modelos americano e indiano, o autor aponta para o fato de que as ações afirmativas estão de alguma forma relacionadas ao nível de centralização e controle do Estado sobre os programas e às possibilidades financeiras de sua execução. Um quadro analítico aponta para os principais impactos (custos e benefícios) objetivos e simbólicos resultantes dos esforços para a inclusão dos de dalits e adivasis no ensino superior.

Essa investigação sobre custos e benefícios pode ser bastante útil no momento para iniciar a avaliação das ações afirmativas no Brasil, pois se até então as medidas orientadas para a inclusão eram ainda pioneiras, estamos hoje diante das primeiras turmas com egressos cotistas que se preparam para o mercado de trabalho. E nesse aspecto o artigo de Weisskopf favorece um diálogo com o texto de Vânia Penha-Lopes em seu esforço para compreender as percepções dos alunos da primeira turma de estudantes cotistas da Universidade Estadual do Rio de Janeiro.
Dessa interseção emerge uma pergunta relevante: qual a "razão" a ser considerada para a relação entre cotas e formação/reforço de identidade racial? Enquanto Weisskopf aponta para uma conexão direta entre inclusão de minorias no ensino superior e consciência em relação à identidade, o texto de Penha-Lopes demonstra, no discurso de alguns alunos cotistas entrevistados, que essa ligação não é necessariamente indissociável. Essa constatação é ao mesmo tempo surpreendente e intrigante, uma vez que tanto defensores como detratores das ações afirmativas creem-nas fortalecedoras de uma identidade racial, o que permitiria o aumento de um capital social potencializador da luta antirracista, no discurso dos defensores, ou levaria a uma racialização perversa e posterior segregação, danosa para a sociedade, no discurso dos detratores.

Mas, de modo geral, o grande trunfo do livro é promover uma apropriação não essencializada sobre o ensino superior.

Considerado como o principal foco de expressão e reprodução de desigualdades, esse setor do ensino revela-se como exemplo mais marcante da disparidade entre brancos e negros, tornando-se o ponto central para os defensores das ações afirmativas. E nesse caso reside uma peculiaridade em relação ao Brasil, pois enquanto, no modelo americano, as medidas de discriminação positiva iniciam-se pelo mercado de trabalho, aqui, precipitam-se pelo campo da educação.

Nesse sentido, os textos apresentados não se circunscrevem à inter-relação da ação afirmativa no ensino superior per si, o que levaria a uma abordagem dos processos objetivos, referentes à entrada e permanência, com a discussão centrada no problema de cotas e cotistas e, mais uma vez, aos estudos de caso isolados. Não que essa abordagem seja obsoleta ou inócua, ao contrário, ela é necessária e não se esgotou, produzindo ainda subsídios 
para o debate. Contudo, no conjunto de artigos apresentados, entende-se que o ensino superior não pode ser exposto ou analisado como um fenômeno social insular, deslocado dos demais fenômenos, tais como a relação com o ensino fundamental e médio, entre dimensões pública e privada, entre escolaridade e mercado de trabalho - como a investigada por Ana Lúcia Sabóia e João Sabóia -, e muitas outras articulações.

Cientes desse fato, os autores propõem, e os artigos interagem, provocando reflexões sobre a ação afirmativa no ensino superior que formam um campo polifônico, mas dialógico. Não por outro motivo, são evidentes as intercessões das pesquisas de Fúlvia Rosemberg e de Valter Roberto Silvério; de Marcelo Paixão e Antonio Sérgio Guimarães; e, por fim, de Daniel Antonio Moraes Sarmento, Luiz Fernando Martins da Silva, Cláudio Pereira de Souza Neto e Sergio Abreu.

Estabelecendo um franco diálogo, esses textos devem ser pensados em blocos de complementaridade que vinculam três eixos temáticos: a relação entre o ensino superior e a pós-graduação; a investigação sobre os componentes ideológicos que alimentam o debate sobre ação afirmativa no Brasil, e, por fim, os princípios jurídicos que envolvem tais políticas.

Decerto a seara que vincula ação afirmativa e pós-graduação é incipiente, quase inexistente no Brasil. E os próprios obstáculos colocados à adoção dessas medidas nas universidades públicas fazem crer que é pouco provável que em um futuro próximo os grandes programas de pós-graduação as adotem.

Contudo, a implementação do International Fellowship Program - IFP [Programa Internacional de Bolsas de Pós-Graduação da Fundação Ford] já ilumina o caminho e, ainda que seja uma experiência isolada por seu pioneirismo, conjuga e sobrepõe diferentes propostas de representatividade (região/sexo/raça).
Neste sentido, os artigos de Fúlvia Rosemberg e de Valter Roberto Silvério complementam-se ao fornecer, por um lado, uma interessante abordagem, até então pouco explorada, sobre metodologias de recrutamento e seleção - o que em algumas experiências de inclusão em universidades públicas revelou-se um calcanhar de Aquiles, como no trabalho de Cláudio Pereira de Souza Neto - e, por outro, um conjunto de sólidos argumentos que ao mesmo tempo problematizam e legitimam a adoção de ações afirmativas na pós-graduação e no ensino superior de forma geral.

Do exercício feito por Valter Roberto Silvério é possível estabelecer uma interlocução com Marcelo Paixão e Antonio Sérgio Guimarães. Seus textos complementamse em uma análise que, ao mesmo tempo, rascunha as historicamente traçadas adesões ideológicas que caracterizam a intelectualidade nacional, e, em um esforço maior, mapeiam os princípios ideológicos que fundamentam os discursos contemporâneos contrários à ação afirmativa no Brasil.

Por fim, o bloco com os artigos de Daniel Antonio Moraes Sarmento, Luiz Fernando Martins da Silva, Cláudio Pereira de Souza Neto e Sergio Abreu discorre sem redundância sobre as questões de ordem jurídica que permeiam o tema. Ao tradicional argumento a respeito da constitucionalidade das ações afirmativas, somam-se análises sobre jurisprudência e sobre os princípios que norteiam a adoção de cotas nas universidades brasileiras. Esses textos podem ser classificados como um manual estratégico para a realização de ações afirmativas, na medida em que, de posse de um sólido material empírico, apresentam e apontam os principais acertos e equívocos cometidos ao longo da luta antirracista.

De modo geral, os artigos ainda trazem algumas questões que irromperam na década que marca a introdução da discussão sobre 
ações afirmativas no Brasil e permanecem atuais, de tal forma que ainda se julga necessária a desconstrução das dicotomias raça/ classe e desigualdades raciais/desigualdades sociais. Para além, persistem as reflexões sobre o sistema de classificação racial, e, evidentemente, ainda se faz sentir a cisão que o tema provocou na intelectualidade brasileira. Tais persistências poderiam representar uma dificuldade de superação das questões abordadas, mas esta seria uma afirmação ingênua. $\mathrm{Na}$ verdade elas indicam que ainda há uma agenda extensa com questões que não foram resolvidas, ou ao menos absorvidas, pelo debate público sobre ações afirmativas, e mostram que esse não alcançou o seu ápice e que, tampouco, as reflexões produzidas sejam as únicas e últimas elaboradas.

\section{Andréa Lopes da Costa Vieira}

Doutora em Sociologia, Coordenadora do Grupo de Estudos e Pesquisas em Políticas Públicas e Desigualdades Sociais, da Escola de Serviço Social, da Universidade do Grande Rio andrea.Icosta@uol.com.br 